\title{
Performance of chromosomal microarray for patients with intellectual disabilities/developmental delay, autism, and multiple congenital anomalies in a Chinese cohort
}

Wilson Wai Sing Chong ${ }^{1,2}$, Ivan Fai Man Lo ${ }^{3}$, Stephen Tak Sum Lam³ ${ }^{3}$ Chi Chiu Wang ${ }^{1,2}$, Ho Ming Luk ${ }^{3}$, Tak Yeung Leung ${ }^{1,2}$ and Kwong Wai Choy ${ }^{1,2,4,5^{*}}$

\begin{abstract}
Background: Chromosomal microarray (CMA) is currently the first-tier genetic test for patients with idiopathic neuropsychiatric diseases in many countries. Its improved diagnostic yield over karyotyping and other molecular testing facilitates the identification of the underlying causes of neuropsychiatric diseases. In this study, we applied oligonucleotide array comparative genomic hybridization as the molecular genetic test in a Chinese cohort of children with DD/ID, autism or MCA.

Results: CMA identified 7 clinically significant microduplications and 17 microdeletions in 19.0\% (20/105) patients, with size of aberrant regions ranging from $11 \mathrm{~kb}$ to $10.7 \mathrm{Mb}$. Fourteen of the pathogenic copy number variant (CNV) detected corresponded to well known microdeletion or microduplication syndromes. Four overlapped with critical regions of recently identified genomic syndromes. We also identified a rare de novo $2.3 \mathrm{Mb}$ deletion at 8p21.3-21.2 as a pathogenic submicroscopic CNV. We also identified two novel CNVs, one at Xq28 and the other at 12q21.31-q21.33, in two patients (1.9\%) with unclear clinical significance. Overall, the detection rate of CMA is comparable to figures previously reported for accurately detect submicroscopic chromosomal imbalances and pathogenic CNVs except mosaicism, balanced translocation and inversion.
\end{abstract}

Conclusions: This study provided further evidence of an increased diagnostic yield of CMA and supported its use as a first line diagnostic tool for Chinese individuals with DD/ID, ASD, and MCA.

Keywords: Chromosomal microarray, Array CGH, Developmental delay, Intellectual disabilities, Multiple congenital anomalies

\section{Background}

Array comparative genomic hybridization (aCGH) and single nucleotide polymorphism (SNP) genotyping array, collectively referred to as chromosomal microarray analysis (CMA), is commonly applied as a clinical diagnostic tool for patients with intellectual disabilities/developmental delay (ID/DD), autism spectrum disorders (ASD), and multiple congenital anomalies (MCA). With rapid advances in

\footnotetext{
* Correspondence: richardchoy@cuhk.edu.hk

'Department of Obstetrics and Gynaecology, The Chinese University of Hong Kong, Hong Kong SAR, China

${ }^{2}$ Prenatal genetic diagnosis laboratory, Prince of Wales Hospital, 30-32 Ngan Shing Street, Shatin, Hong Kong SAR, China

Full list of author information is available at the end of the article
}

microarray resolution and throughput over the past few years, CMA has consistently shown a higher diagnostic yield than conventional karyotyping [1-5]. The International Collaboration for Clinical Genomics (ICCG), also known as International Standard for Cytogenomic Array (ISCA) Consortium, has recommended CMA over the karyotyping as the first-tier cytogenetic diagnostic test for patients with ID/DD and MCA [6]. Standards and guidelines recommended by American College of Medical Genetics (ACMG) have also been publised to standardise and improve the quality of CMA among different clinical genetic laboratories $[7,8]$. 
Rare copy number variants (CNV) have been implicated in the pathogenesis of many neuropsychiatric diseases despite the appreciation of the abundance of common CNVs in normal individuals [9,10]. Several studies have elucidated the causative role of $\mathrm{CNV}$ in DD/ID, ASD [11], congenital heart diseases [12], epilepsy [13], and congenital kidney malformation [14]. However, these studies also illustrated the phenotypic heterogeneity associated with a particular CNV. That is, the same CNV may confer risk to multiple diseases; other additional risk factors are required for the development of a specific disease outcome. This has led to the "two-hit" theory $[15,16]$. Under this circumstance, the clinical diagnosis, genetic counseling and management become challenging. An evidence-based approach which is dependent on the accumulation and delivery of knowledge through internet resources has been established to facilitate the result interpretations $[17,18]$.

In this study, a high resolution $180 \mathrm{~K}$ oligonucleotideCMA was applied in a Chinese cohort of patients with DD/ID, ASD, and MCA. The CMA findings were interpreted using the evidence-based workflow as recommended by ICCG and ACMG for molecular diagnosis of constitutional chromosomal and subchromosomal imbalances.

\section{Results}

\section{CMA validation}

To validate the CMA platform in this study, we first tested 10 cases of numerical chromosomal abnormalities including 7 trisomy cases $(13,16,18,21$ and 22) and 3 monosomy cases $(18,21$ and $\mathrm{X})$. Subsequently 10 normal cases by karyotyping of normal individual were also included in the validation set. The CMA results were in $100 \%$ concordnace with karyotyping. The final set included 10 cases with known microscopic or submicroscopic chromosomal abnormalities (7 by karyotyping, 2 by multiplex ligation-dependent probe amplification, and one by multiplex ligation-dependent probe amplification and fluorescence in situ hybridization). Pathogenic $\mathrm{CNV}$ (pCNV) were detected in 7 cases (Additional file 1) and were concordant with the previous findings. The remaining cases without $\mathrm{pCNV}$ detected by CMA were mosaic marker chromosome, balanced structural rearrangement of chromosome 4 , and balanced inversion of chromosome 12.

\section{Detection rate of pathogenic CNV in a postnatal cohort}

A total of 105 patients with MR/DD/ASD/MCA referred to clinical genetics service were recruited for CMA application study. Custom-designed arrays precluding most of benign CNV as catalogued by Database of Genomic Variants (DGV) were applied in 67 patients (63.8\%) while ISCA array were used in another 38 patients (36.2\%). The average numbers of CNV found per patient using custom-designed array and ISCA array were 3 CNVs and 16 CNVs, respectively.

The detection rates of pathogenic CNV from customdesigned and ISCA array were $17.9 \%$ and $21.1 \%$, respectively, with an overall detection rate of $19.0 \%$. A total of 24 CNVs (7 microduplications and 17 microdelections) in 20 patients were considered pathogenic (Figure 1). The size of the pathogenic $\mathrm{CNV}$ (pCNV) ranged from $11 \mathrm{~kb}$ to $7.1 \mathrm{Mb}$ (Additional file 2). Recurrent pCNV were most frequently observed at the 22q11.2 region in this cohort, with two 22q11.2 duplications (MIM 608363) and three 22q11.2 deletions (Velocardiofacial/ DiGeorge syndrome; MIM 188400) being identified. Deletions in the chromosomal region of 2q37.1-q37.3 known to cause the brachydacytly-mental retardation syndrome were the second most common pCNV. Three patients carried the submicroscopic deletions with an overlapping region of $2.7 \mathrm{Mb}$ encompassing the critical HDAC4 gene which is responsible for the phenotype. Three cases of pCNV each corresponding to PraderWilli syndrome (MIM 176270), WAGR syndrome (MIM 612469), and 3q29 microdeletion (MIM 609425) were also identified.

Seven cases bearing rare CNV which overlapping with the critical regions of emerging genetic syndromes were identified and were considered pathogenic. These including five microdeletions (1q21.3-q22, 4q35.2, 10q23.1, 14q22.1-q22.3 and 21q22.13) and two microduplications (17q25.1-q25.3 and 13q21.2) as reported previously (Additional file 2). One patient was diagnosed with moderate DD, autistic features, hypotonia, and dermoid cyst over scalp. CMA showed a de novo $2.3 \mathrm{Mb}$ deletion at 8p21.3-21.2 encompassing 37 genes. Although there was no known microdeletion syndrome associated with this region, we considered it pathogenic based on its size, de novo nature, and its overlapping with $70 \%$ of the pathogenic variant found in one DD + DM case (nssv578268) from the ISCA database and a similar 8p21 microdeletion being reported in a patient with ID and behavioral abnormalities.

There were two cases with duplication and deletion of size 1.33 and $6.22 \mathrm{Mb}$, respectively that were considered to bear a variant of unclear clinical significance (VOUS). The first case (aCGH3704) carried a $6.22 \mathrm{Mb}$ deletion at 12q21.31-q21.33. The microdeletion was inherited from a physiologically healthy father and the patient does not carry any symptoms related to Bardet-Biedl syndrome. Bardet-Biedl syndrome is typically inherited in an autosomal recessive manner. For the second case (aCGH1293), it carries a $1.33 \mathrm{Mb}$ microduplication containing the $M E C P 2$ region. The $\mathrm{X}$-chromosome inactivation $(\mathrm{XCI})$ pattern has not been analyzed in the female patient and the GDI1 gene was not involved, therefore we regarded these two microduplications as VOUS. 

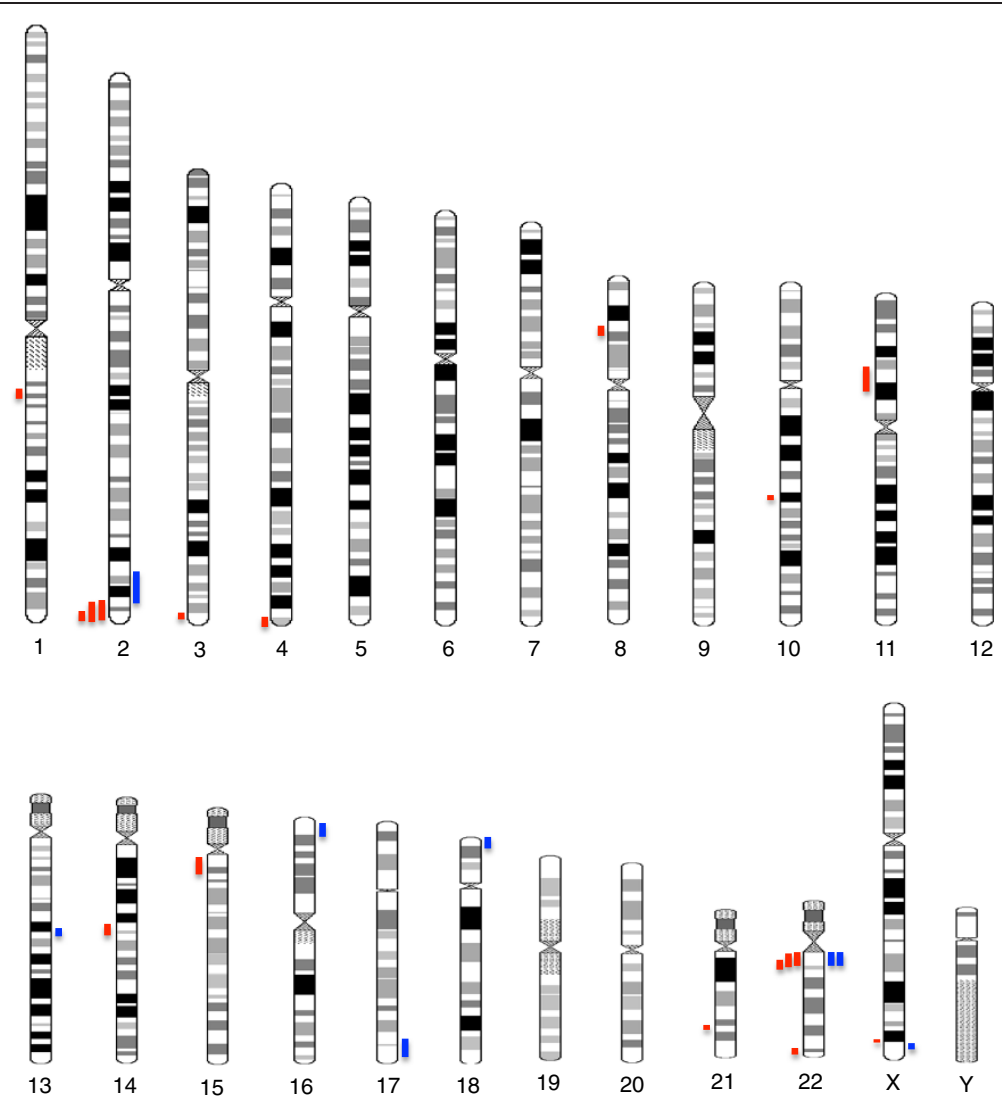

Figure 1 An overview of pathogenic CNV found in this study. Copy number loss is shown as red (left) and copy number gain in blue (right), respectively. The length of the bar indicating the size of each aberrant region.

\section{Discussion}

This is the first study describing the use of CMA in a Chinese cohort of patients with DD/ID, MCA, and autism referred for clinical genetics testing. The CMA platform was first validated in patients with known abnormal cytogenetic and molecular findings. Microscopic or submicroscopic chromosomal imbalances were accurately detected by CMA with improved resolution, the breakpoints of aberrant regions could be more precisely defined (Additional file 1). The advantage of increased precision in delineation of breakpoints facilitates the identification of the disease-causing genes [6]. The superiority of CMA over karyotyping has also been demonstrated in several cases. For instance, in a case of marker chromosome of unknown origin detected by karyotyping, CMA detected a 7.4 Mb duplication at 15q11.2-q13.1. This provided a clue to the origin of the marker chromosome and explained the phenotype of 15q11-q13 duplication syndrome as observed in this patient. In another patient with normal karyotype, CMA revealed a complex chromosome rearrangement involving a $10.7 \mathrm{Mb}$ duplication at 2q36.1-q37.1 and a 9.7 $\mathrm{Mb}$ deletion at 2q37.1-q37.3. The size of individual aberration was clearly within the detection range by karyotyping (>5 Mb). However, the close proximity of these two aberrant regions resulting in small net gain of genomic materials $(<1 \mathrm{Mb})$ which precluded its detection by karyotyping. In general, the limitations of CMA including its inability to detect low level mosaicism, heterochromatic abberrations, inversion and balanced translocation, were inherent to this platform $[6,19]$.

In this study, twenty patients (19.0\%) with DD/ID, ASD, and MCA were found to have at least one pathogenic CNV. The detection rate achieved in this study was similar to previous studies irrespective of the choice of oligonucleotide-based (13-28\%) [20-26] or SNP-based platforms (15-19\%) [27-29]. Improvement in the diagnostic yield of CMA is initially contributed by the increased genomic coverage and resolution of oligonucleotide arrays over bacterial artificial chromosome (BAC) arrays among aCGH platforms [30]. Both lower probe density and difference in genomic coverage may contribute to the lower detection rate. This is exemplified by the lower probe density custom designed $44 \mathrm{~K}$ array used in the majority of the cases which might contributed to a lower positive rate (17.9\%) as expected compared to the higher density probe ISCA $180 \mathrm{~K}$ design (21.1\%,). However, the smaller size of CNV identified were mostly benign. This is in 
concordance with previous reports indicated that most pathogenic $\mathrm{CNV}$ are $>400 \mathrm{~kb}$ in size [6]. Our data suggested that appropriate size filter could be introduced to decrease the false positive calls.

Fourteen pCNV corresponded to the well known microdeletion or microduplication syndromes were identified. Velocardiofacial/DiGeorge syndrome, 22q11.2 duplication, brachydacytly-mental retardation syndrome, and PraderWilli syndrome were among the most common recurrent genomic disorders observed in many different populations. They are known to be mediated by nonallelic homologous recombination (NAHR) between regions of segmental duplication. Our results also indicated that the pathogenic $\mathrm{CNV}$ associated with DD/ID, autism, and MCA were also largely contributed by NAHR in our study cohort.

We identified a rare microduplictaion (a de novo 2.3 Mb duplication) at 16p13.3 in a patient with dysmorphism, mild MR, camptodactyly, tracheomalacia in early childhood, blepharophimosis, and ptosis in adulthood. This region encompasses the CREBBP gene. Deletion of this gene is known to cause Rubinstein-Taybi syndrome [31] while its duplication is responsible for the observed phenotypes in chromosome 16p13.3 duplication syndrome which occurs in a frequency of 1 in 97,000 to 146, 000 live births [32].

Two CNV were classified as VOUS in two female patients. A de novo Xq28 duplication was identified in a patient with mild DD, DM, MCA, and hypotonia (Additional file 2). Xq28 duplication syndrome (MIM 300815) was first suspected given the cytoband location and the observed phenotype of DD. However, detailed genomic location as depicted by CMA showed that the critical $0.3 \mathrm{Mb}$ region of Xq28 including the GDI1 gene was not involved in our case. Instead, the duplicated region encompassed another set of genes which are known to cause several genomic syndromes only when they are deleted or mutated. In addition, there were no report of case with similar duplications from ISCA or DECIPHER database. In the second case, a paternally inherited deletion of 12q21.31-q21.33 was found in a patient with ID and DM. Although the father was phenotypically normal, the pathogenicity of this region could not be excluded. Homozygous deletion of CEP290 (OMIM*610142) and ALX1 (OMIM*601527) in this region are associated with different neurological diseases, but our case is a gain of copy number. Therefore, we considered these two microduplication regions as VOUS.

\section{Conclusions}

In summary, our study has demonstrated the success of CMA application in patients with DD/ID, ASD, and MCA of a Chinese cohort. The interpretation of CMA findings was facilitated by publicly available databases, such as ISCA, DECIPHER, and DGV.

\section{Methods}

\section{Patients}

One hundred and fifteen patients with ID, DD, autism, or MCA from Clinical Genetic Service of the Department of Health of Hong Kong were recruited, both prospectively and retrospectively, in this study (IRB approval: LM/283/2010). All patients and their parents were studied by conventional karyotyping to exclude any inherited microscopic chromosomal abnormalities or balanced carrier status. Ten of them who had known genomic imbalances based on prior cytogenetic and/or molecular findings were chosen for platform validation. In addition, 10 prenatal samples with known numerical chromosomal abnormalities and 10 samples from adults with normal karyotype were recruited for the validation study. Another 105 patients without prior knowledge of genomic aberrations were recruited for application study and investigated by validated CMA. Informed consent was obtained from parents or guardians. Ethical approval of the study protocol was obtained from Ethics Committee of the Department of Health, Hong Kong. DNA was extracted from peripheral blood using DNeasy blood \& tissue kit (Qiagen) according to manufacturer's instructions. Genomic DNA concentration was measured by Nanodrop spectophotometer (ThermoFisher).

\section{CMA}

The aCGH platform from Agilent Technologies was employed in this study. Custom-designed $44 \mathrm{~K}$ as described previously [33] and ISCA designed $180 \mathrm{~K}$ oligonucleotide microarrays were used. Both designs had similar genomic coverage for interrogation of over 100 genetic disorders but were different in probe density giving average genome-wide resolution of $100 \mathrm{~kb}$ and $25 \mathrm{~kb}$, respectively.

Experimental procedures were performed according to manufacturer's description. Briefly, one microgram of patient's DNA and normal female control DNA (Promega) were differentially labeled with $\mathrm{Cy} 5$ and $\mathrm{Cy} 3$ respectively using Agilent SureTag Complete DNA Labeling Kit (Agilent Technologies, USA). Labeled DNA was then cleaned by purification columns (Agilent Technologies, USA) and hybridized on microarray for 24 hours. Microarray washing and scanning was performed using Agilent Oligo aCGH Wash Buffers (Agilent Technologies, USA) and Agilent Microarray Scanner (Agilent Technologies, USA) according to manufacturer's instructions. All pathogenic CNVs were further validated on NimbleGen CGX-135 K array which were designed by Signature Genomics (Perkin Elmer, USA) following manufacturer's instructions.

\section{Data analysis}

Microarray images were processed with Feature Extraction v.11.1 (Agilent Technologies, USA) and imported to Agilent Genomic Workbench 7.0.4.0 for analysis. CNV 
were identified and curated to minimise false positive calls. Specifically, any aberration call with less than five probes and the value of $\log _{2}$ ratio in gain $<0.25$ or loss $<0.5$ was filtered. Parental aCGH were also performed to determine the origin of $\mathrm{CNV}$ if needed. $\mathrm{CNV}$ were considered pathogenic if they overlapped with the critical regions of well-characterized duplication/deletion syndromes or pathogenic regions as reported in ISCA or DatabasE of Chromosomal Imbalance and Phenotype in Humans using Ensembl Resources (DECIPHER) database, or were relatively large and encompassing many genes. Benign CNVs are those frequently seen among healthy individuals in the normal population as catalogued in the DGV. CNVs that contained a small number of genes but did not overlap with regions of known duplication/deletion syndrome, and that were not normal CNVs reported in the DGV, were regarded as VOUS (variant of uncertain clinical significance).

\section{Additional files}

Additional file 1: Validation of CMA platform using samples with abnormal results in previous test.

Additional file 2: CMA with pCNV or VOUS findings for chinese cohort of patients with intellectual disabilities/developmental delay, autism and MCA. Notes: NA = not applicable [34-40].

\section{Abbreviations}

aCGH: Array comparative genomic hybridization; SNP: Single nucleotide polymorphism; CMA: Chromosomal microarray analysis; DD/ID: Developmental delay/intellectual disability; ASD: Autism spectrum disorders; MCA: Multiple congenital anomalies; ICCG: International collaboration for clinical genomics; ISCA: International standard for cytogenomic array; ACMG: American college of medical genetics; CNV: Copy number variant; pCNV: Pathogenic copy number variant; VOUS: Unclear clinical significance; BAC: Bacterial artificial chromosome; DM: Dysmorphism

\section{Competing interests}

The authors declare that they have no competing interests.

\section{Authors' contributions}

WC carried out the microarrays analysis and drafted the manuscript. IFML, HML, and STSL clinically examined the patients and collected clinical data. CCW performed molecular cytogenetic analysis and revised the manuscript. KWC and TYL conceived the work, and participated in its design, draft and revised the manuscript. All authors read and approved the final manuscript.

\section{Acknowledgements}

This work was supported by Health and Health Services Research Fund (08090401) and the National Basic Research Program of China (81370715).

\footnotetext{
Author details

'Department of Obstetrics and Gynaecology, The Chinese University of Hong Kong, Hong Kong SAR, China. ${ }^{2}$ Prenatal genetic diagnosis laboratory, Prince of Wales Hospital, 30-32 Ngan Shing Street, Shatin, Hong Kong SAR, China. ${ }^{3}$ Clinical Genetic Service, Department of Health, Hong Kong SAR, China. ${ }^{4}$ CUHK-Shenzhen Research Institute, The Chinese University of Hong Kong, Shenzhen, China. ${ }^{5}$ Joint Centre with Utrecht University-Genetic Core, School of Biomedical Science, The Chinese University of Hong Kong, Hong Kong SAR, China.
}

Received: 7 November 2013 Accepted: 6 May 2014

Published: 23 May 2014

\section{References}

1. Friedman JM, Baross A, Delaney AD, Ally A, Arbour L, Armstrong L, Asano J, Bailey DK, Barber S, Birch P, Brown-John M, Cao M, Chan S, Charest DL, Farnoud N, Fernandes N, Flibotte S, Go A, Gibson WT, Holt RA, Jones SJ, Kennedy GC, Krzywinski M, Langlois S, Li Hl, McGillivray BC, Nayar T, Pugh TJ, Rajcan-Separovic $\mathrm{E}$, Schein JE, et al: Oligonucleotide microarray analysis of genomic imbalance in children with mental retardation. Am J Hum Genet 2006, 79:500-513.

2. Rauch A, Hoyer J, Guth S, Zweier C, Kraus C, Becker C, Zenker M, Huffmeier $U$, Thiel C, Ruschendorf F, Nurnberg P, Reis A, Trautmann U: Diagnostic yield of various genetic approaches in patients with unexplained developmental delay or mental retardation. Am J Med Genet A 2006, 140A:2063-2074.

3. Lu X, Shaw CA, Patel A, Li J, Cooper ML, Wells WR, Sullivan CM, Sahoo T, Yatsenko SA, Bacino CA, Stankiewicz P, Ou Z, Chinault AC, Beaudet AL, Lupski JR, Cheung SW, Ward PA: Clinical implementation of chromosomal microarray analysis: summary of 2513 postnatal cases. PLoS One 2007, 2:e327.

4. Lu XY, Phung MT, Shaw CA, Pham K, Neil SE, Patel A, Sahoo T, Bacino CA, Stankiewicz P, Kang SH, Lalani S, Chinault AC, Lupski JR, Cheung SW Beaudet AL: Genomic imbalances in neonates with birth defects: high detection rates by using chromosomal microarray analysis. Pediatrics 2008, 122:1310-1318.

5. Shao L, Shaw CA, Lu XY, Sahoo T, Bacino CA, Lalani SR, Stankiewicz P, Yatsenko SA, Li Y, Neill S, Pursley AN, Chinault AC, Patel A, Beaudet AL, Lupski JR, Cheung SW: Identification of chromosome abnormalities in subtelomeric regions by microarray analysis: a study of 5,380 cases. Am J Med Genet A 2008, 146A:2242-2251.

6. Miller DT, Adam MP, Aradhya S, Biesecker LG, Brothman AR, Carter NP, Church DM, Crolla JA, Eichler EE, Epstein CJ, Faucett WA, Feuk L, Friedman JM, Hamosh A, Jackson L, Kaminsky EB, Kok K, Krantz ID, Kuhn RM, Lee C, Ostell JM, Rosenberg C, Scherer SW, Spinner NB, Stavropoulos DJ, Tepperberg JH, Thorland EC, Vermeesch JR, Waggoner DJ, Watson MS, et al: Consensus statement: chromosomal microarray is a first-tier clinical diagnostic test for individuals with developmental disabilities or congenital anomalies. Am J Hum Genet 2010, 86:749-764.

7. Kearney HM, Thorland EC, Brown KK, Quintero-Rivera F, South ST, Working Group of the American College of Medical Genetics Laboratory Quality Assurance C: American College of Medical Genetics standards and guidelines for interpretation and reporting of postnatal constitutional copy number variants. Genet Med 2011, 13:680-685.

8. Kearney HM, South ST, Wolff DJ, Lamb A, Hamosh A, Rao KW: American College of Medical Genetics recommendations for the design and performance expectations for clinical genomic copy number microarrays intended for use in the postnatal setting for detection of constitutional abnormalities. Genet Med 2011, 13:676-679.

9. Lee C, lafrate AJ, Brothman AR: Copy number variations and clinical cytogenetic diagnosis of constitutional disorders. Nat Genet 2007, 39:S48-S54.

10. Cooper GM, Coe BP, Girirajan S, Rosenfeld JA, Vu TH, Baker C, Williams C, Stalker H, Hamid R, Hannig V, Abdel-Hamid H, Bader P, McCracken E, Niyazov D, Leppig K, Thiese H, Hummel M, Alexander N, Gorski J, Kussmann J, Shashi V, Johnson K, Rehder C, Ballif BC, Shaffer LG, Eichler EE: A copy number variation morbidity map of developmental delay. Nat Genet 2011, 43:838-846.

11. Wisniowiecka-Kowalnik B, Kastory-Bronowska M, Bartnik M, Derwinska K, Dymczak-Domini W, Szumbarska D, Ziemka E, Szczaluba K, Sykulski M, Gambin T, Gambin A, Shaw CA, Mazurczak T, Obersztyn E, Bocian E, Stankiewicz P: Application of custom-designed oligonucleotide array CGH in 145 patients with autistic spectrum disorders. Eur J Hum Genet 2012, 21:620-625.

12. Syrmou A, Tzetis M, Fryssira H, Kosma K, Oikonomakis V, Giannikou K, Makrythanasis P, Kitsiou-Tzeli S, Kanavakis E: Array comparative genomic hybridization as a clinical diagnostic tool in syndromic and nonsyndromic congenital heart disease. Pediatr Res 2013, 73:772-776.

13. Bartnik M, Szczepanik E, Derwinska K, Wisniowiecka-Kowalnik B, Gambin T, Sykulski M, Ziemkiewicz K, Kedzior M, Gos M, Hoffman-Zacharska D, Mazurczak T, Jeziorek A, Antczak-Marach D, Rudzka-Dybala M, Mazurkiewicz H, Goszczanska-Ciuchta A, Zalewska-Miszkurka Z, Terczynska I, Sobierajewicz M, Shaw CA, Gambin A, Mierzewska H, Mazurczak T, Obersztyn E, Bocian E, Stankiewicz P: Application of array comparative genomic hybridization in 102 patients with epilepsy and additional neurodevelopmental disorders. Am J Med Genet B Neuropsychiatr Genet 2012, 159B:760-771. 
14. Sanna-Cherchi S, Kiryluk K, Burgess KE, Bodria M, Sampson MG, Hadley D, Nees SN, Verbitsky M, Perry BJ, Sterken R, Lozanovski VJ, Materna-Kiryluk A, Barlassina C, Kini A, Corbani V, Carrea A, Somenzi D, Murtas C, RistoskaBojkovska N, Izzi C, Bianco B, Zaniew M, Flogelova H, Weng PL, Kacak N, Giberti S, Gigante M, Arapovic A, Drnasin K, Caridi G, et al: Copy-number disorders are a common cause of congenital kidney malformations. Am J Hum Genet 2012, 91:987-997.

15. Girirajan S, Rosenfeld JA, Cooper GM, Antonacci F, Siswara P, Itsara A Vives L, Walsh T, McCarthy SE, Baker C, Mefford HC, Kidd JM, Browning SR, Browning BL, Dickel DE, Levy DL, Ballif BC, Platky K, Farber DM, Gowans GC, Wetherbee JJ, Asamoah A, Weaver DD, Mark PR, Dickerson J, Garg BP, Ellingwood SA, Smith R, Banks VC, Smith W, et al: A recurrent 16p12.1 microdeletion supports a two-hit model for severe developmental delay. Nat Genet 2010, 42:203-209.

16. Girirajan S, Rosenfeld JA, Coe BP, Parikh S, Friedman N, Goldstein A, Filipink RA, McConnell JS, Angle B, Meschino WS, Nezarati MM, Asamoah A, Jackson KE, Gowans GC, Martin JA, Carmany EP, Stockton DW, Schnur RE, Penney LS, Martin DM, Raskin S, Leppig K, Thiese H, Smith R, Aberg E, Niyazov DM, Escobar LF, El-Khechen D, Johnson KD, Lebel RR, et al: Phenotypic heterogeneity of genomic disorders and rare copy-number variants. N Engl J Med 2012, 367:1321-1331.

17. Riggs ER, Chruch DM, Hanson K, Horner VL, Kaminsky EB, Kuhn RM, Wain KE, Williams ES, Aradhya S, Kearney HM, Ledbetter DH, South ST, Thorland EC, Martin CL: Towards an evidence-based process for the clinical interpretation of copy number variation. Clin Genet 2012, 81:403-412.

18. Wei Y, Xu F, Li P: Technology-driven and evidence-based genomic analysis for integrated pediatric and prenatal genetics evaluation. J Genet Genomics 2013, 40:1-14.

19. Bi W, Borgan C, Pursley AN, Hixson P, Shaw CA, Bacino CA, Lalani SR, Patel A, Stankiewicz P, Lupski JR, Beaudet AL, Cheung SW: Comparison of chromosome analysis and chromosomal microarray analysis: what is the value of chromosome analysis in today's genomic array era? Genet Med 2012, 15:450-457.

20. Hochstenbach R, Van Binsbergen E, Engelen J, Nieuwint A, Polstra A, Poddighe P, Ruivenkamp C, Sikkema-Raddatz B, Smeets D, Poot M: Array analysis and karyotyping: workflow consequences based on a retrospective study of 36,325 patients with idiopathic developmental delay in the Netherlands. Eur J Med Genet 2009, 52:161-169.

21. Siggberg L, Ala-Mello S, Jaakkola E, Kuusinen E, Schuit R, Kohlhase J, Bohm $D$, Ignatius J, Knuutila S: Array CGH in molecular diagnosis of mental retardation - a study of 150 Finnish patients. Am J Med Genet A 2010, 152A:1398-1410.

22. Hayashi S, Imoto I, Aizu Y, Okamoto N, Mizuno S, Kurosawa K, Okamoto N, Honda S, Araki S, Mizutani S, Numabe H, Saitoh S, Kosho T, Fukushima Y, Mitsubuchi H, Endo F, Chinen Y, Kosaki R, Okuyama T, Ohki H, Yoshihashi H, Ono M, Yagi M, Matsumoto H, Makita Y, Hata A, Inazawa J: Clinical application of array-based comparative genomic hybridization by two-stage screening for 536 patients with mental retardation and multiple congenital anomalies. J Hum Genet 2011, 56:110-124.

23. Wincent J, Anderlid BM, Lagerberg M, Nordenskjold M, Schoumans J: High-resolution molecular karyotyping in patients with developmental delay and/or multiple congenital anomalies in a clinical setting. Clin Genet 2011, 79:147-157.

24. lourov IY, Vorsanova SG, Kurinnaia OS, Zelenova MA, Silvanovich AP, Yurov YB: Molecular karyotyping by array CGH in a Russian cohort of children with intellectual disability, autism, epilepsy and congenital anomalies. Mol Cytogenet 2012, 5:46.

25. Callier P, Aral B, Hanna N, Lambert S, Dindy H, Ragon C, Payet M, CollodBeroud G, Carmignac V, Delrue M, Goizet C, Philip N, Busa T, Dulac Y, Missotte I, Sznajer Y, Toutain A, Francannet C, Megarbane A, Julia S, Edouard T, Sarda P, Amiel J, Lyonnet S, Cormier-Daire V, Gilbert B, Jacquette A, Heron D, Collignon $P$, Lacombe D, et al: Systematic molecular and cytogenetic screening of 100 patients with marfanoid syndromes and intellectual disability. Clin Genet 2013, 84(6):507-21.

26. Rodriguez-Revenga L, Vallespín E, Madrigal I, Palomares M, Mur A, GarcíaMiñaur S, Santos F, Mori MÁ, Lapunzina P, Mila M, Nevado J: A parallel study of different array-CGH platforms in a set of Spanish patients with developmental delay and intellectual disability. Gene 2013, 521:82-86.

27. Bruno DL, Ganesamoorthy D, Schoumans J, Bankier A, Coman D, Delatycki M, Gardner RJ, Hunter M, James PA, Kannu P, McGillivray G, Pachter N, Peters H, Rieubland C, Savarirayan R, Scheffer IE, Sheffield L, Tan T, White SM, Yeung A, Bowman Z, Ngo C, Choy KW, Cacheux V, Wong L, Amor DJ,
Slater HR: Detection of cryptic pathogenic copy number variations and constitutional loss of heterozygosity using high resolution SNP microarray analysis in 117 patients referred for cytogenetic analysis and impact on clinical practice. J Med Genet 2009, 46:123-131.

28. Friedman JM, Adam S, Arbour L, Armstrong L, Baross A, Birch P, Boerkoel C, Chan S, Chai D, Delaney AD, Flibotte S, Gibson WT, Langlois S, Lemyre E, Li HI, MacLeod P, Mathers J, Michaud JL, McGillivray BC, Patel MS, Qian H, Rouleau GA, Van Allen MI, Yong SL, Zahir FR, Eydoux P, Marra MA: Detection of pathogenic copy number variants in children with idiopathic intellectual disability using $500 \mathrm{~K}$ SNP array genomic hybridization. BMC Genomics 2009, 10:526.

29. McMullan DJ, Bonin M, Hehir-Kwa JY, De Vries BB, Dufke A, Rattenberry E, Steehouwer M, Moruz L, Pfundt R, De Leeuw N, Riess A, Altug-Teber O, Enders $\mathrm{H}$, Singer $\mathrm{S}$, Grasshoff U, Walter M, Walker JM, Lamb CV, Davison EV, Brueton L, Riess O, Veltman JA: Molecular karyotyping of patients with unexplained mental retardation by SNP arrays: a multicenter study. Hum Mutat 2009, 30:1082-1092.

30. Toruner GA, Streck DL, Schwalb MN, Dermody JJ: An oligonucleotide based array-CGH system for detection of genome wide copy number changes including subtelomeric regions for genetic evaluation of mental retardation. Am J Med Genet A 2007, 143A:824-829.

31. Tsai AC, Dossett CJ, Walton CS, Cramer AE, Eng PA, Nowakowska BA, Pursley AN, Stankiewicz P, Wiszniewska J, Cheung SW: Exon deletions of the EP300 and CREBBP genes in two children with Rubinstein-Taybi syndrome detected by aCGH. Eur J Hum Genet 2011, 19:43-49.

32. Thienpont B, Béna F, Breckpot J, Philip N, Menten B, Van Esch H, Scalais E, Salamone JM, Fong CT, Kussmann JL, Grange DK, Gorski JL, Zahir F, Yong SL, Morris MM, Gimelli S, Fryns JP, Mortier G, Friedman JM, Villard L, Bottani A, Vermeesch JR, Cheung SW, Devriendt K: Duplications of the critical Rubinstein-Taybi deletion region on chromosome $16 \mathrm{p} 13.3$ cause a novel recognisable syndrome. J Med Genet 2010, 47:155-161.

33. Leung TY, Vogel I, Lau TK, Chong W, Hyett JA, Petersen OB, Choy KW: Identification of submicroscopic chromosomal aberrations in fetuses with increased nuchal translucency and apparently normal karyotype. Ultrasound Obstet Gynecol 2011, 38:314-319.

34. Reddy S, Dolzhanskaya N, Krogh J, Velinov M: A novel 1.4 Mb de novo microdeletion of chromosome 1q21.3 in a child with microcephaly, dysmorphic features and mental retardation. Eur J Med Genet 2009, 52:443-445.

35. Cuturilo G, Menten B, Krstic A, Drakulic D, Jovanovic I, Parezanovic V, Stevanovic M: 4q34.1-q35.2 deletion in a boy with phenotype resembling 22q11.2 deletion syndrome. Eur J Pediatr 2011, 170:1465-1470.

36. Youngs EL, Henkhaus RS, Hellings JA, Butler MG: 12-year-old boy with a 4q35.2 microdeletion and involvement of MTNR1A, FAT1, and F11 genes. Clin Dysmorphol 2012, 21:93-96.

37. Van Bon BW, Balciuniene J, Fruhman G, Nagamani SC, Broome DL, Cameron E, Martinet D, Roulet E, Jacquemont S, Beckmann JS, Irons M, Potocki L, Lee B, Cheung SW, Patel A, Bellini M, Selicorni A, Ciccone R, Silengo M, Vetro A, Knoers NV, De Leeuw N, Pfundt R, Wolf B, Jira P, Aradhya S, Stankiewicz P, Brunner HG, Zuffardi O, Selleck SB, et al: The phenotype of recurrent 10q22q23 deletions and duplications. Eur J Hum Genet 2011, 19:400-408

38. Vorstman JA, Van Daalen E, Jalali GR, Schmidt ER, Pasterkamp RJ, De Jonge M, Hennekam EA, Janson E, Staal WG, van der Zwaag B, Burbach JP, Kahn RS, Emanuel BS, Van Engeland H, Ophoff RA: A double hit implicates DIAPH3 as an autism risk gene. Mol Psychiatry 2011, 16:442-451.

39. Hayashi S, Okamoto N, Makita Y, Hata A, Imoto I, Inazawa J: Heterozygous deletion at 14q22.1-q22.3 including the BMP4 gene in a patient with psychomotor retardation, congenital corneal opacity and feet polysyndactyly. Am J Med Genet A 2008, 146A:2905-2910.

40. Valetto A, Orsini A, Bertini V, Toschi B, Bonuccelli A, Simi F, Sammartino I, Taddeucci G, Simi P, Saggese G: Molecular cytogenetic characterization of an interstitial deletion of chromosome 21 (21q22.13q22.3) in a patient with dysmorphic features, intellectual disability and severe generalized epilepsy. Eur J Med Genet 2012, 55:362-366.

doi:10.1186/1755-8166-7-34

Cite this article as: Chong et al:: Performance of chromosomal microarray for patients with intellectual disabilities/developmental delay, autism, and multiple congenital anomalies in a Chinese cohort. Molecular Cytogenetics 2014 7:34. 